\title{
Itaguaí, ou o grande teatro do mundo
}

\section{Pierre Brunel}

Tradução e notas de Jean Pierre Chauvin

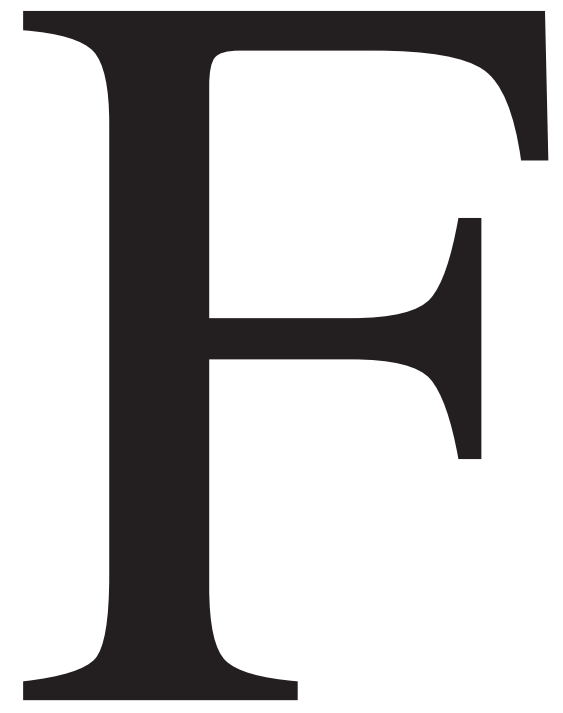

\section{SOBRE A QUESTÃO DA LOUCURA}

Com o título original "Itaguaï, ou le grand théâtre du monde", o presente texto foi publicado como apresentação à versão francesa de $O$ alienista, de Machado de Assis (L'Aliéniste, Paris, Métailié, 1984, pp. 9-23). Somos muito gratos a Pierre Brunel por nos ter autorizado a traduzir e veicular o seu ensaio.

1 A Loucura, narradora do Elogio da loucura (1511), de Erasmo de Roterdã.

PIERRE BRUNEL é crítico literário e pesquisador da área de Literatura Comparada, tendo sido professor na Universidade de Sorbonne, Paris IV, entre 1970 e 2008. É autor de, entre outros, Dictionnaire de Don Juan (Robert Laffont). 
a sua glória. Os clínicos substituíram a linguagem $d a$ loucura pela linguagem sobre a loucura. Seus adversários quiseram demonstrar que a loucura só existia graças à linguagem da demência, "a doença mental constituída pelo conjunto do que era dito no grupo de todos os enunciados que a nomearam, a recortavam, a descreviam, a explicavam, relatando seus desenvolvimentos, indicando suas diversas correlações, julgando-a e eventualmente emprestando-lhe a sua palavra articulando em seu nome discursos que deveriam passar como se fossem os seus" (Michel Foucault, Arqueologia do saber). O homem do nosso tempo ainda se encontra frente a um dilema entre as duas soluções apresentadas claramente por Michel Serres, em Hermes I: "Falar sobre a desrazão" - é o discurso do médico; "deixar a não razão falar por si mesma" [é] uma deriva que conduz a literatura moderna, no limite, de Hölderlin a Antonin Artaud.

Como vários escritores do século XIX, Machado de Assis escolheu uma terceira via, a do discurso. A ele pareceu que isso permitiria manter certa distância, sem recair na frieza do discurso científico. A narração está isenta de todos os prestígios da noite, do satanismo, de "O elixir do diabo" ou do maravilhoso "A fada das migalhas". Contrariamente a Hoffmann $^{2}$ ou a Nodier ${ }^{3}$, ele organiza a apresentação não em torno do alienado,

2 Ernst Theodor Amadeus Wilhelm Hoffmann (17761822), autor do conto "O elixir do diabo".

3 Charles Nodier (1780-1844), autor do conto "A fada das migalhas". mas do alienista. O fato é que esse alienista pode ser um alienado e ser situado na mesma linha daqueles sábios loucos de feição cada vez mais inquietante, nos romances do final do século. O Tribulat Bonhomet, de Villiers de l'Isle-Adam, positivista ávido de "coisas verdadeiras", acaba com medo do barulho do vento, da sombra de um pássaro...

A distância entre a literatura e a loucura tende a se reduzir, ou até mesmo ser anulada, quando o discurso está em primeira pessoa. Em Aurélia, Nerval não só atravessa as portas de marfim e de chifre, esse próprio limite o separa deste “outro" que é o seu eu objetivado. Em "O Horla", Maupassant induz o narrador ao suicídio; então, a sua fala se apaga. Da mesma forma, o Diário de um louco, de Gogol, só poderia destiná-lo ao silêncio. Em $O$ alienista, Machado de Assis segue os preceitos do discurso em terceira pessoa. Porém, quando as portas da Casa Verde se fecham sobre Simão Bacamarte, interrogamo-nos sobre a relação que poderia haver entre a personagem e este romancista que tanto amava as máscaras. De fato, a novela é uma obra de resistência contra o que Michel Foucault chamaria de "alienações que curam" - ou melhor, que pretendem curar. Mas, como pode ela [a obra] resistir, sem dar palavra à loucura? Simão Bacamarte fala pouco: é o segredo da sua força, quando os adversários o atacam. Podemos captar um fragmento de seu monólogo interior, particularmente quando toma a decisão final. Mas de onde Machado de Assis fala, de que lugar do discurso romanesco, sobre qual situação da palavra? 


\section{DISTINÇÃO [LA CÉSURE]}

Em 1881, O alienista era contemporâneo do ilustre Jean-Marie Charcot ${ }^{4}$, que se torna uma personagem literária. Portanto, Machado de Assis remete-nos a "tempos remotos" que talvez não estivessem ligados somente a uma ficção cômoda - aquela em que os discursos são pretensamente baseados em um manuscrito encontrado ou remetido, arrancados à poeira da crônica.

De regresso a Itaguaí, Ítaca brasileira, após um longo período de estudos na Europa, Simão Bacamarte traz consigo uma das invenções mais tristes do começo do século, a estrutura manicomial [asilaire]. No final de História da loucura na Idade Clássica, Michel Foucault chamou a atenção para a importância dos decretos adotados pela Assembleia Constituinte, em 12 e 16 de março de 1790, e o espírito em que tais decisões foram tomadas. Libertar os internados de Bicêtre ${ }^{5}$ era impedir que se confundissem por mais tempo os loucos com os prisioneiros em geral. Aos primeiros, deveria ser reservado um tratamento especial, o hospital. Aquilo a que chamamos pudicamente de "Casa de Saúde" (Casa da Esperança, Casa Verde...) foi concebido ao longo de dois séculos, e durante muito tempo o modelo era o asilo de York, fundado por Samuel Tuke ${ }^{6}$.

4 Médico e cientista francês considerado um dos grandes nomes da neurologia (1825-1893).

5 Inaugurado em 1742, o Hospital Bicêtre se situa na comuna francesa Le Kremlin-Bicêtre.

6 Filantropo inglês que reformou o asilo de York. Viveu entre 1784 e 1857.
Simão é mais do que um discípulo de Tuke, ou de Pinel, ou dos célebres doutores Blanche ${ }^{7}$, que se revezavam em Montmartre e Passy, para cuidar de Gérard de Nerval. Ele é prisioneiro em sua própria vila; uma espécie de inventor do asilo. Ele abandona seus mestres de Coimbra e Pádua imediatamente para enveredar pela escola dos pensadores árabes. Averróis não tinha mais segredos para ele que para o doutor Fausto. Bacamarte se refere até mesmo ao Corão. Autodidata duas vezes diplomado, ele extrai da reflexão pessoal o projeto da Casa Verde, submete-o à Vereança de Itaguaí, que o avaliza dando-lhe magnitude imprevisível.

Esse médico é, antes de tudo, um homem da teoria. Desde o início do empreendimento, ele parte de um postulado que é precisamente aquele na nova divisão: aquilo que Michel Foucault chamou "o limite que estabelece a distância entre razão e desrazão". A primeira surpresa advém da "torrente de loucos" que, muito rapidamente, se espalha na Casa Verde. É por isso que ele concebe uma "teoria nova", apresentada no capítulo IV: a ilha da loucura é um continente. A ideia de divisão é mantida: dividir a razão e a loucura é análogo a separar a terra das águas. O princípio da distinção é simples, e o alienista pode expô-lo ao compadre boticário: "A razão é o perfeito equilíbrio de todas as faculdades; fora daí insânia, insânia e só insânia”.

Até aí, pareceria que ele fora levado à teoria em consequência da prolifera-

7 Dinastia de médicos que viveu na França entre os séculos XVIII e XIX. 
ção de fatos. Mas rapidamente passamos a suspeitar que ele os multiplicava para alimentar o próprio sistema. A linha divisória [entre loucura e sanidade] recua sem cessar, como se o desequilíbrio não fosse mais do que um conceito flutuante sobre o oceano da razão científica. Poder-se-ia esperar por uma ampliação da teoria que abolisse a cesura. Mas uma outra "teoria nova", aquela do capítulo XI, mantém o limite e propõe uma simples inversão: os estados de desequilíbrio são declarados "normais" e, contrariamente, o equilíbrio perfeito é considerado como índice de um risco patológico. O alienista não deixa de acreditar na cesura, como todos aqueles que, desde o final do século XVIII, trabalhavam pela constituição da loucura como doença mental e estabeleceram "a constatação de um diálogo rompido" entre a razão e a desrazão.

A partir daí, Simão Bacamarte vigia ciosamente esse limite. Não que ele tema pelas pessoas normais: ele só se preocupa com os loucos de que está encarregado. A terapia de internação não admite a menor exceção, a menor diferença. Não haverá mais inocentes livres em Itaguaí; por isso vemos o médico a "correr pela multidão um olhar inquieto e policial, não era outra coisa mais do que a ideia de que algum demente podia achar-se ali misturado com a gente de juízo". O limite da internação condiz com o que Simão Bacamarte cria ler nos fatos. Essa mimese confere à cura uma magia que o cientista resistiria em admitir.

Homem da ciência, o alienista nada possui de um sujeito do diálogo. Sua esposa, Dona Evarista, é apenas uma presença desde sempre inoportuna a seu lado. Ela só vê "lunáticos" onde ele detecta loucos. Lunáticos, como sugere Daniel Cameron no início de "A fada das migalhas", são homens chamados assim "porque se ocupam tão pouco dos negócios deste mundo porque descendem da lua" e porque só falam "de coisas que jamais poderiam se passar em parte nenhuma, se não fosse a lua". Dona Evarista renega o limite para o qual o seu implacável marido a empurra. Ela deixa de entender as especulações dele, que não admite o gosto dela pelos bibelôs. Não existe relação "conjugal”, exceto quando ele a interna porque ela não conseguia se decidir entre um colar de granadas e um de safira. Além disso, Simão Bacamarte concebera um ideal de vida a dois para o boticário e sua esposa, na Casa Verde.

Simão Bacamarte não admite mais o diálogo consigo mesmo. O dilema de Evarista se torna insuportável. A seu turno, ficará impaciente diante do impasse em que se encontrará na hora da dúvida, quando "teve duas sensações contrárias, uma de gozo, outra de abatimento". O homem que atribui limites não pode aceitar a cisão nele mesmo. Por isso, ele se condena à internação, quer dizer, à solidão definitiva, e ainda mais profunda, na Casa Verde.

\section{O MÉDICO LOUCO}

O narrador de "A fada das migalhas" visita uma casa de dementes em Glasgow. "Lunático voluntário", ele mesmo vem a "reclamar desses mal-afortunados direitos de simpatia". Mas o mais louco de todos que ele encontra é um "horrível homem 
negro" que o atordoa com seus discursos pedantescos com a pretensão de poder explicar tudo. Aprendizado tomado, trata-se de um "famoso médico de Londres que viera fazer observações filantrópicas na casa de Glasgow, para aplicá-las no aperfeiçoamento da ciência e no destino de todos os doentes dos três reinos".

Igualmente, desde o princípio, no discurso de Machado de Assis suspeitamos que o fundador da Casa Verde é mais louco que os seus pacientes. Desde o dia em que ele propõe a nova instituição à Câmara Municipal: "A ideia de meter os loucos na mesma casa, vivendo em comum, pareceu em si mesma sintoma de demência". Na verdade, Itaguaí vivia, havia décadas, no torpor rotineiro de uma pequena vila de província, onde nada acontecia, senão nascimentos, casamentos e falecimentos. Por pouco não nos cremos na aldeia de Vondervotteimittiss, imaginada por Edgar Allan Poe em "O diabo no campanário", cuja regra de ouro, fixada pela Câmara Municipal, é de que seria "um crime alterar o bom e velho andamento das coisas".

A insinuação ganha força quando se constata o que há de maníaco no comportamento de Simão Bacamarte. Desde os primórdios da experiência, "a paciência do alienista" parecia ser "ainda mais extraordinária do que todas as manias hospedadas na Casa Verde": paciência para coletar os dados, organizar a vida material e os atendimentos, classificar os casos (há uma verdadeira mania taxonômica em Simão Bacamarte, assim como nos médicos do século XIX).

Se o cenário da mania justapõe sem os reunir "de um lado, um mundo en- charcado, quase diluviano, onde o homem continua sendo surdo, cego e adormecido diante de tudo o que não é seu pânico aterrorizante; de outro, um mundo ardente e desértico, um mundo em pânico onde tudo é escoamento, desordem, fluidez instantânea" (Michel Foucault), a visão interior de Simão comporta uma dicotomia similar: aqueles que partiram ao Rio de Janeiro não contam mais; ele só enxerga os habitantes da Casa Verde, imagem ideal de Itaguaí, reduzida somente aos casos interessantes.

À proporção que reúne um número crescente de pacientes em seu asilo, Simão Bacamarte se envolve cada vez mais. $\mathrm{O}$ alienista não trata mais os loucos; ele os fabrica. As hipóteses se multiplicam e a menor delas não passa de uma "monomania do próprio médico". O vereador dissidente, Sebastião Freitas, pergunta aos seus colegas: "[...] se tantos homens em quem supomos são reclusos por dementes, quem nos afirma que o alienado não é o alienista?".

Essa é a conclusão a que Simão Bacamarte chega por conta própria, não em decorrência de uma progressão, mas como consequência de uma palinódia ${ }^{8}$.

Ele não se torna ciente da sua demência por descobrir uma fissura secreta no seu íntimo, nem se inquieta diante de uma hipertrofia monstruosa; acredita reconhecer em si mesmo todas as características do equilíbrio moral, o mais realizado, inclusive a modéstia. Não é difícil notar algum desequilíbrio nesse equilíbrio.

\footnotetext{
8 Mudança brusca de concepção; retratação.
} 
Enxergando-se como portador de todas as qualidades possíveis, o que é confirmado por aqueles que compreenderam que esse era seu tendão de Aquiles, Simão Bacamarte cede diante de uma contemplação narcisista de si mesmo que só pode precipitá-lo no espelho da loucura (o tema do lago/espelho, tão frequente na literatura da loucura no século XIX, particularmente em "A queda da casa de Usher", aconteceria por acaso?). Desde o início da novela, adivinhamos nele uma megalomania que não para de crescer. Quando inaugurada, a Casa Verde lhe parecia uma "espécie de mundo, em que há o governo temporal", que ele aceita confiar aos outros, "e o governo espiritual", que ele não delega a ninguém.

Papa do asilo? - ele não hesita em atribuir a Benedito VIII, diante do padre Lopes, uma afirmação do Corão sobre a qual fundamenta o seu empreendimento. Deus do asilo? - como ele não cederia à tentação de acreditar nisso, já que atribuía a si mesmo o poder de reformar os seres e lhes dar um novo nascimento? Então, ele reúne em sua loucura um dos seus pacientes, João de Deus, que "dizia agora ser o deus João, e prometia o reino dos céus a quem o adorasse, e as penas do inferno aos outros".

\section{AS DUAS PRISÕES}

Ao isolar um interno do resto da humanidade e do mundo, a Casa Verde merece receber apenas um nome: prisão. Essa é toda a diferença existente entre a casa do carpinteiro Zimmer, refugiado de Hölderlin, e o asilo de Northampton, onde John Clare foi trancado. A tomada da Bastilha não foi suficiente ou o processo não chegou a seu termo. Como observou Michel Foucault, só podemos falar sobre a liberação dos internos de Bicêtre por antífrase. A esse respeito, a Revolução foi em vão.

Na novela de Machado de Assis, o médico rival de Simão Bacamarte, um confrade invejoso porque não tinha clínica, é o primeiro a semear a opinião segundo a qual "a Casa Verde é um cárcere privado". Há um rumor quando Mateus é preso, culpado por superestimar a causa própria.

Pouco a pouco, a opinião se espalha. E quando o barbeiro Porfírio assume a cabeça da revolta, dá o sinal do que deve ser a tomada da "Bastilha da Razão Humana". De uma revolução a outra, só haveria a distância que existe entre Paris e Itaguaí, e "os trezentos que caminhavam para a Casa Verde [...] podiam ser comparados aos que tomaram a Bastilha”. Os Canjicas são os sans-cullote da razão ameaçada.

Mas há um momento perturbador em $O$ alienista. Isso acontece quando Porfírio e seus acólitos invadem a sede da Câmara e ordenam que os eleitos se retirassem "dali para a prisão". Qual? O edifício da vila previsto para os condenados de foro comum e os detentos políticos? Ou a Casa Verde, outra vez? Desse modo, os habitantes de Itaguaí esperam ser logo libertados daquele ser que se tornara a sua obsessão. Toda a vila respira ao imaginar que, em 24 horas, o alienista seria colocado nas grades e haveria "a destruição da Casa Verde". Uma prisão substitui a outra. É o retorno ao Antigo Regime. Em todo caso, é na ordem do discurso que se dá o encontro frente a frente das duas prisões. Qual delas prevalecerá? Essa é a 
nova questão que, durante algum tempo, dará nova orientação ao drama. De uma prisão a outra: acresce que, sob o aval da história, a ameaça é a mesma e se compreende que, nas cidades do futuro, imaginadas pela literatura utópica, o asilo será substituído pela prisão. E por que não considerar apenas os livros, tendo em vista que a própria história contemporânea concede ao espaço carcerário a forma da internação psiquiátrica?

\section{INFERNO E PARAÍSO}

O asilo-prisão não é uma balbúrdia como o hospital geral. A ciência moderna se orgulha de saber classificar os casos, e esta é uma das primeiras questões de Simão Bacamarte. Como no Inferno de Dante ou como no estabelecimento de Santa Brígida, no início de Meteoros, de Michel Tournier, os círculos são desenhados: aquele dos loucos furiosos, aquele dos inocentes, aquele dos monomaníacos. Ainda se trata da singela apresentação que o narrador faz. Pode-se imaginar que o alienista se ocupa em estabelecer distinções mais sutis e que se afinam, à medida que a experiência se prolonga: a princípio, duas grandes classes; depois, subclasses; em seguida, sub-subclasses onde os casos, sempre aberrantes, encontram cada vez maior dificuldade para ter lugar.

Mesmo quando agrupa os loucos em um conjunto, em um continente, o alienista se depara com a singularidade individual. A estrela de Vênus, o criminoso errante, o maníaco por genealogia, o pródigo que vive em bandos, todos esses casos atípicos constituem numerosos enigmas.
A ciência se desgasta em busca de uma chave compatível com um tipo.

Quando a "família dos deserdados" estiver "completa", será um inferno a desfilar sob nossos olhos. O discurso de Machado de Assis não foge à catalogação, que é o modo obrigatório de toda apresentação infernal. Ele concorre com a situação encontrada nos registros do asilo, no livro do Inferno. O encarceramento já é um inferno. "Creio", escrevia John Clare em julho de 1848, "que faz aproximadamente dois anos que me enviaram para este Inferno que não me permite atravessar as grades. Jamais houve pior frustração que este lugar”.

Quando a teoria do alienista muda, uma reversão se produz. A Casa Verde não acolhe mais os vícios aparentes, mas as qualidades superiores, as virtudes mais raras e, por isso, as mais inquietantes. "Os alienados foram alojados por classes. Fez-se uma galeria de modestos; isto é, os loucos em quem predominava esta perfeição moral; outra de tolerantes, outra de verídicos, outra de símplices, outra de leais, outra de magnânimos, outra de sagazes, outra de sinceros, etc."

No total, sete círculos que são, dessa vez, aqueles de um Paraíso. A perfeição do edifício exige que, assim como na Divina Comédia, Deus coroe o todo. Esse Deus só pode ser o próprio alienista, detentor do poder espiritual. Mas ele é um Deus que se acha sozinho no outro mundo deserto.

\section{"RINOCERITE" E TERROR}

Nos últimos Cantos de Maldoror, Deus é representando como um rinoceronte cego 
e furioso. A novela de Machado de Assis leva a pensar em outros rinocerontes, ainda que o alienista deva figurar, no final, como o Rinoceronte supremo. A epidemia de "rinocerite", que Eugênio Ionesco representou inicialmente em uma novela e depois, em 1959, numa peça de teatro, não difere essencialmente da epidemia de loucura descrita em Itaguaí.

O primeiro lance é feito pelas famílias, muito felizes por se livrarem tanto de um louco violento, até então retido na despensa, quanto de um inocente abandonado à sua vadiagem. Dessa primeira divisão, desse primeiro encarceramento, Simão Bacamarte é mais herdeiro que responsável. Se ele, muito rapidamente, reúne "uma torrente de loucos" é porque a doença progride no momento em que é reconhecida; sobretudo, porque a covardia humana rendeu-se muito rapidamente, após algumas reticências, às razões de uma medicina favorável ao séquito do paciente, em vez de provar que ela própria lhe poderia ser útil.

A primeira teoria, formulada por $\mathrm{Si}$ mão Bacamarte no capítulo IV, incita-o a prender em sua rede todas as presas que pudesse recolher. Ele está atento ao primeiro índice, assim como ao primeiro bubão, em tempo de peste, ou à primeira inflamação de pele, de onde sairá o chifre do rinoceronte: a prodigalidade do Costa, a superstição da sua cozinha... Um dos momentos mais impressionantes a esse respeito é aquele em que o presidente da Câmara é declarado portador da "demência dos touros" por ter dito, em plena sessão, que só se contentaria com pelo menos 30 "almudes" de sangue, para lavar a afronta imposta pelos Canjicas. É a partir desse momento que a coleta de loucos perde o freio.

Teria o alienista inventado esses sinais? Antes disso, é uma outra "rinocerite" que ele lhes oferece: sempre a covardia complacente dos habitantes de Itaguaí. De fato, o alienista não precisa sair em busca de novos casos. Eles são entregues em domicílio. Acusam-no de exercer o Terror. Mas ele mesmo é ultrapassado pelo Terror que se instala e que se deve muito menos à sua vontade tirânica que à obediência daqueles que estão à frente de suas ordens e desejos. O clímax acontece quando uma nuvem de bajuladores e caluniadores assedia a vila. O presidente da Câmara é denunciado pelo relator da reunião.

Em seguida, diante dessas circunstâncias, a personalidade aparentemente engraçada do boticário Crispim Soares pode ganhar certo relevo. Esse M. Hormais ${ }^{9}$ de Itaguaí seguia o alienista de bom grado. Mas quando ele crê no triunfo dos Canjicas, não resiste mais: entrega-se no Palácio do Governo para fazer aliança com Porfírio, o mestre da ocasião. Em tempos de Terror, essa personagem tranquila poderia ser mais perigosa que os colaboradores mais atuantes.

O fato é que o alienista fará com que prendam Crispim Soares, alegando, satisfeito, que o terror também é pai da loucura. O pavor é uma das marcas nos contos de Maupassant. Mas dificilmente ele pode ser considerado um critério seguro. O diagnóstico do médico sofre

9 Farmacêutico personagem do romance Madame Bovary (1857), de Gustave Flaubert. 
uma reviravolta quando a norma fixada inicialmente (o limite entre o equilíbrio e o desequilíbrio) se revela ultrapassada, subvertida por uma pesquisa apaixonada e fanática do caso. Então, tudo pode vir a ser indício suficiente, tudo pode ser pretexto para a internação. A história do nosso século ensinou-nos dolorosamente. O apólogo de Machado de Assis descreve, antecipadamente, a engrenagem de nossos Terrores modernos.

Não conheço, no livro, episódio mais impressionante que o enigma do anel de prata. Ele acontece quando a caça aos loucos atinge o auge, em sua figuração mais perversa. Ao levar a Câmara a votar uma ordenação que autorizasse o porte de um anel de prata no polegar da mão esquerda a toda pessoa que declarasse ter duas ou três onças de sangue azul, Simão Bacamarte faz as vontades de um amigo ourives a quem a manobra, de fato, enriquece. Mas, de resto, o comportamento [de Bacamarte] não autoriza, de forma alguma, hipótese semelhante a seu respeito. Seria preferível considerar o resultado: todos aqueles que portam o anel são internados. Não há efeito mágico, como se poderia pensar. Mas esse é o sinal, suscitado, imposto sob a cor de um pseudovoluntário, pelo detector de anomalias, pelo maníaco da internação. Estaremos nós tão distantes da estrela amarela ${ }^{10}$, da grande confusão para fins de separação que servia de suporte ao Terror nazista? Não acredito...

10 Referência à estrela de Davi, usada pelos judeus durante o nazismo alemão, por ordem do III Reich.

\section{A SÁTIRA POLÍTICA}

Em outro tempo, em outro país, Machado de Assis superou o problema do racismo. Ele sabia que a América Latina estava tão sujeita aos abalos do regime quanto aos tremores de terra. A vila de Itaguaí se torna uma alegoria política transparente em absoluto.

A invocação de Simão instaura uma crise da qual tentam se aproveitar aqueles que gostam do poder. Quando Porfírio assume como cabeça dos revoltosos, é mais levado pela ambição que sente tomar conta de si do que pela questão em causa a que pretende servir: "Pareceu-lhe então que, demolindo a Casa Verde e derrocando a influência do alienista, chegaria a apoderar-se da Câmara".

O capítulo IX reserva boas surpresas. A começar pelo título: "Dois lindos casos", dois novos casos patológicos que fazem a alegria do alienista. Um é o do Porfírio, outro é o da população de Itaguaí, que o apoiou. Simão constata a desenvoltura de um e a debilidade do outro. Mas o episódio é mais notável ainda devido à retratação [palinodie] do barbeiro. Acreditava-se que ele tivesse ido à Casa Verde para proceder à prisão de Simão - o próprio alienista esperava por isso. Porém, o novo chefe do governo insurrecional tem em vista um acordo com o homem da ciência, que ele quer cooptar como homem do poder.

Durante a disputa, ele se contentará com um "arranjo intermediário": não está seguro de que a opinião pública tenha razão em acreditar que os internados estejam em plena posse de seu discerni- 
mento. De toda maneira, o domínio da ciência pertence aos sábios e os governantes respeitam a fronteira. O erro é da equipe municipal precedente. A Casa Verde havia se tornado uma instituição de utilidade pública. Ela resultara, portanto, em uma potência política: não será combatida; não será deixada em situação adversa; daí aliar-se com o alienista, que poderia ser um considerável reforço contra os inimigos, em potencial, do novo regime. Algumas frases de Porfírio, diante de Simão Bacamarte, lembram a cautela dos políticos, os vícios das pretensas democracias que só se apoiam na vontade do povo para traí-lo.

Simão enxerga um caso patológico na duplicidade do barbeiro de Itaguaí, que logo sustenta um discurso diferente perante o povo.

Mas, antes de tudo, trata-se de um caso político, aliás recorrente. $\mathrm{O}$ maquiavelismo de pouco alcance não vinga: o alienista se recusa a ceder e vai além, a ponto de internar 50 partidários do novo regime; um outro barbeiro substitui o primeiro e aprende, igualmente, com o poder. $\mathrm{O}$ grande golpe de Porfírio chegara tarde demais. Mas a comédia importa mais que a tragédia: Porfírio sai ileso da aventura e ganha sabedoria, inclusive. O ciúme do "rival da navalha", João Pina, é o contraponto burlesco do ciúme do médico, que tenta atribuir precipitadamente o descrédito à Casa Verde. De certo modo, poder-se-ia julgar Simão Bacamarte mais digno: ele não acusa o "golpe" e continua sendo o mestre, de modo que, ao final, decide a sorte de si mesmo e do seu reinado, ainda que não fosse mais que uma waste land.

\section{PODER E DESAFIO PELA PALAVRA}

Seria o alienista aquele que vigia a loucura, que a fabrica ou que dela padece? O título, revisto à luz da narrativa, revela a fragilidade de qualquer denominação. Mas a força [da novela] não é menor. O poder do alienista advém mais do novo nome que dá às coisas que do nome que damos a ele. Mateus ama a sua casa em demasia: o fabricador de selas é taxado como obcecado pelas pedras. Evarista se preocupa demais com suas roupas e joias: sua coqueteria torna-se "mania suntuária" e ela se torna passível de internação. O espírito revanchista de um membro do governo merece a mesma sorte quando é chamado de "demência dos touros".

Dá-se o mesmo em política. Toda mudança recebe nova denominação. Porfírio faz-se chamar "Protetor da vila em nome de Sua Majestade e do povo". Concede-se Senhoria, Chefe, até mesmo Majestade. Por sua vez, ele confere o mesmo tratamento ao alienista, por vê-lo como um soberano com quem manterá uma relação.

Simão Bacamarte não pode ser vítima da retórica de usurpação. Desde muito tempo ele suspeitava que houvesse, na eloquência inflada, um caso de lesão cerebral. Por isso mesmo, Martim Brito foi enviado à Casa Verde, e com ele seu tesouro de hipérboles, negras quando se tratava de celebrar a queda do Marquês de Pombal; rosas, quando era necessário ressaltar os atrativos (portanto, duvidosos) de Dona Evarista...

Como é derrisória e, portanto, como é potente essa retórica! Bastou que Porfírio emprestasse a imagem de um poeta 
local e a repetisse com uma bela ênfase, para que levasse todo o povo ao assalto da "Bastilha"... Mesmo Simão não recua diante de metáforas fáceis: a imagem da pérola (que encontramos - até em Karl Jaspers! ${ }^{11}$ - naqueles que creem que a loucura cria o gênio) designa a região, produto dessa vasta concha que é o espírito humano.

Dentre a galeria de maníacos, não se deve negligenciar aquele rapaz rude e grosseiro que, todos os dias, após o almoço, lançava-se sob uma arenga das mais acadêmicas, pontuada por tropos, antíteses e apóstrofes, recamada de graça e latim, recheada de citações de Cícero, Apuleio e Tertuliano. O padre Lopes procura por uma explicação no mito da Torre de Babel: "Provavelmente, confundidas antigamente as línguas, é fácil trocá-las agora, desde que a razão não trabalhe...”. Mas parece igualmente irracional que a palavra seja controlada, ou não, pela pretensiosa razão.

\section{HETERÔNIMO}

O que está colocado em questão é a linguagem, portanto - a começar pela utilizada pelo escritor. Sem dúvida, Machado impôs a cura pela sobriedade, nessa breve narrativa reduzida ao essencial. De fato, o seu discurso não está inflado, senão de efeitos irônicos (“o ilustre médico, com os olhos acesos da convicção científica, trancou os ouvidos à saudade da mulher, e brandamente a repeliu").

11 Karl Theodor Jaspers (1883-1969), filósofo e psiquiatra alemão.
Permanece a linguagem do autor, em um discurso diferente.

Desde sua estreia no jornalismo, Machado de Assis manteve o hábito e o gosto por utilizar pseudônimos. Ele será Brás Cubas, Dom Casmurro, Aires, sem que nenhuma dessas três figuras se confunda com a precedente. O alienista nasce do anonimato nas crônicas de Itaguaí, e nada indica que Simão Bacamarte seja, ele mesmo, o narrador-testemunha dessa história. Teria ele tempo ou força para tanto, durante os 17 meses de existência que o romancista lhe deixa, após a sua internação? Aquele período foi inteiramente consagrado ao estudo da sua cura e, de fato, escrever a própria história assume valor heurístico, virtude catártica. Porém, o final da narrativa não evoca o início e, a despeito de algumas semelhanças (a falta de perspectiva, por exemplo), Simão Bacamarte figura como outra máscara, um novo heterônimo de Machado de Assis.

Portanto, o romancista ambientou a personagem na situação em que ele adorava colocar os seus porta-vozes. Seu olhar superior permite enxergar os demais como fantoches ridículos e absurdos. É que Simão Bacamarte está exatamente no centro do dispositivo. De seu observatório na Casa Verde ele percebe toda a população de Itaguaí. Ninguém poderá escapar ao seu olhar inquisitivo. Além disso, todos os habitantes da vila passam - eu ia dizer caem na armadilha - pelo asilo. A mudança da teoria tem a vantagem de permitir a inclusão das exceções.

Nesse livro reside a condição sem-fim da loucura; aquilo que Gilles Deleuze, numa página da Lógica do sentido, consagrada a Nietzsche, chamou de "sem 
fundo". E, como Nietzsche, Machado de Assis se diverte em torno do "sem fundo", o que nos faz sorrir, sob o risco de ele mesmo entrar na pantomima.

A amostragem é tão completa que nos oferece a imagem de toda a humanidade, e Itaguaí representa o grande teatro do mundo.
Por intermédio do alienista, o romancista aplica um novo olhar sobre a comédia humana. Talvez ele tenha percebido, assim como Nietzsche, o olhar da loucura erasmiana. Discernir tantas loucuras é enlouquecer. Simão se encerra na Casa Verde. Machado de Assis escreve a palavra FIM. 